\title{
Large Scale Fabrication of Ordered Gold Nanoparticle-Epoxy Surface Nanocomposites and Their Application as Label-Free Plasmonic DNA Biosensors
}

\author{
Tomáš Lednický and Attila Bonyár* \\ Cite This: ACS Appl. Mater. Interfaces 2020, 12, 4804-4814 \\ Read Online
}

ACCESS | Lلll Metrics \& More | 回 Article Recommendations | st Supporting Information

ABSTRACT: A robust and scalable technology to fabricate ordered gold nanoparticle arrangements on epoxy substrates is presented. The nanoparticles are synthesized by solid-state dewetting on nanobowled aluminum templates, which are prepared by the selective chemical etching of porous anodic alumina (PAA) grown on an aluminum sheet with controlled anodic oxidation. This flexible fabrication technology provides proper control over the nanoparticle size, shape, and interparticle distance over a large surface area (several $\mathrm{cm}^{2}$ ), which enables the fine-tuning and optimization of their plasmonic absorption spectra for LSPR and SERS applications between 535 and $625 \mathrm{~nm}$. The nanoparticles are transferred to the surface of epoxy substrates, which are

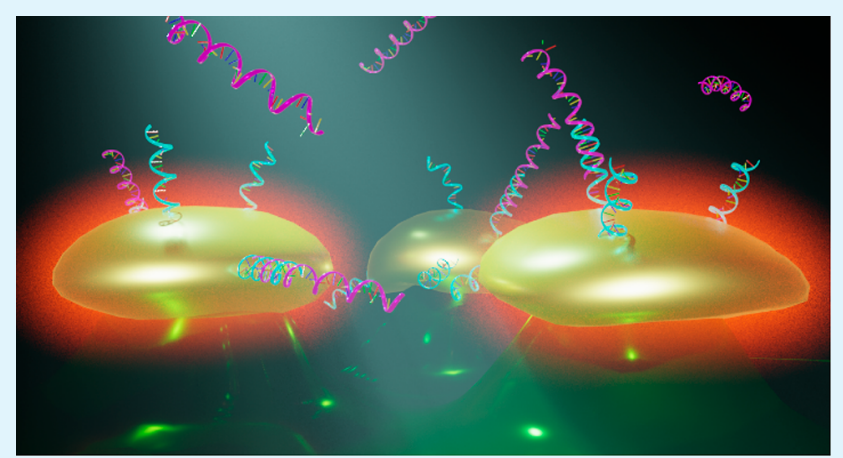
subsequently selectively etched. The resulting nanomushrooms arrangements consist of ordered epoxy nanopillars with flat, disk-shaped nanoparticles on top, and their bulk refractive index sensitivity is between 83 and $108 \mathrm{~nm} \mathrm{RIU}{ }^{-1}$. Label-free DNA detection is successfully demonstrated with the sensors by using a 20 base pair long specific DNA sequence from the parasite Giardia lamblia. A red-shift of $6.6 \mathrm{~nm}$ in the LSPR absorbance spectrum was detected after the $2 \mathrm{~h}$ hybridization with $1 \mu \mathrm{M}$ target DNA, and the achievable LOD was around $5 \mathrm{nM}$. The reported plasmonic sensor is one of the first surface AuNP/polymer nanocomposites ever reported for the successful label-free detection of DNA.

KEYWORDS: localized surface plasmon resonance, nanoparticle lattice, DNA biosensor, surface nanocomposite, nanobowled aluminum

\section{INTRODUCTION}

Surface plasmon polaritons (SPPs) are the collective oscillation of delocalized electrons at a metallic surface in response to an external electric field. Since their first application for sensing purposes in the early $1980 \mathrm{~s},{ }^{1}$ surface plasmon resonance (SPR) based instruments became one of the most widely used tools of our time for the label-free characterization of biomolecular interactions. ${ }^{2}$ The major advantages of SPR based chemical and biosensors are their excellent sensitivity (even in the range of $\left.10^{-7} \mathrm{RIU}\right)^{3}$ to the changes in the refractive index of the medium close to the metal-dielectric interface and that they yield real-time information regarding the molecular interactions. Also, by use of a defocused laser illumination and a CCD camera as a detector, it is possible to image a larger area of the sensor surface, which enables a high-throughput multianalyte/multibiosensor concept, called SPR imaging. ${ }^{4}$ Besides the obvious success and the widespread distribution of SPRi instruments, a disadvantage of the configuration is that the classical Kretschmann-type reflective optical setup is hard to be integrated into small, hand-held point-of-care (PoC) devices, which is the main reason for the comparatively limited success of integrated SPR constructions ${ }^{5-8}$ and for the lack of hand-held SPRi devices on the market. The most significant difference between LSPR and classic SPR is that localized surface plasmon resonance on nanoparticles is more easily excitable, and thus simpler measurement configurations can be used. ${ }^{, 10}$ In the chip based LSPR setup the nanoparticles are used on a surface of a transparent substrate; ${ }^{10}$ the transmissive optical setup enables the integration of this principle into small, hand-held point-of-care LSPR imaging devices. ${ }^{11,12}$

There are several recent reviews focusing on the advances of plasmonic nanoparticle ${ }^{13,14}$ and nanoarray ${ }^{15}$ based LSPR sensors and their application for biosensing purposes. Out of these applications, label-free DNA sensing is one of the most challenging because of the inherently small size of target molecules. Although higher bulk RI sensitivity generally means higher sensitivity to target molecules, the relationship between the RI sensitivity and molecular sensitivity is not trivial in LSPR. The reported bulk RI sensitivity values ${ }^{16}$ for LSPR sensors range between 71 and $1933 \mathrm{~nm} \mathrm{RIU}^{-1}$, and although it

Received: November 17, 2019

Accepted: January 6, 2020

Published: January 6, 2020 


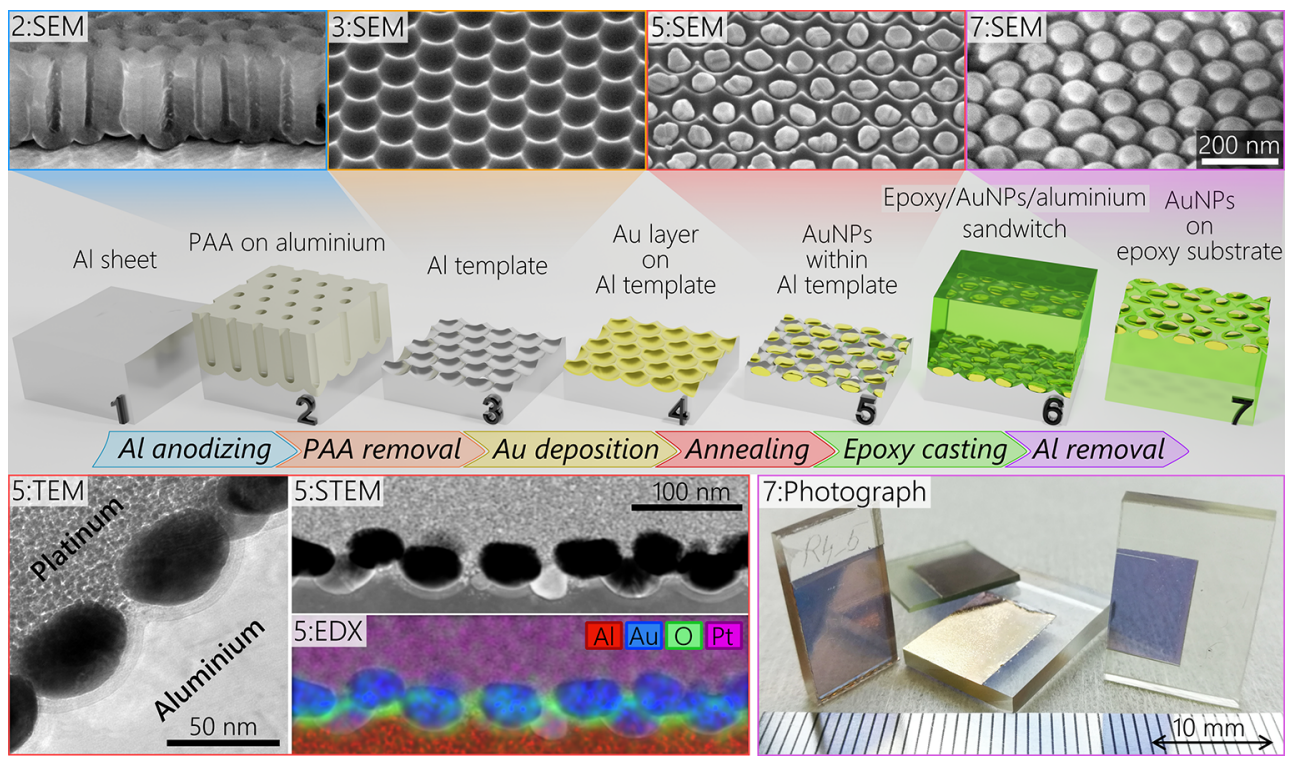

Figure 1. Comprehensive illustration of the technology to fabricate ordered nanoparticle arrangements on epoxy substrates. The main steps of the process are the following: (1) Preparation (cleaning, mechanical and electrochemical polishing) of the Al sheets. (2) Formation of PAA on aluminum through controlled anodic oxidation. (3) Nanobowled aluminum template formation after PAA removal. (4) Thin film deposition of gold on the template. (5) Nanoparticle arrangement formation through solid-state dewetting. (6) Epoxy casting and curing on top of the gold arrangement. (7) After the removal of the $\mathrm{Al}$ sheet the nanoparticles are transferred to the epoxy substrate. The SEM/TEM/EDX/optical images illustrate the various phases of fabrication.

can still be considered low compared to the equivalent bulk refractive index sensitivity of thin film based classical SPR instruments (which can be above $3300 \mathrm{~nm} \mathrm{RIU}{ }^{-1}$ ), ${ }^{17}$ concerning molecular sensitivity, LSPR can match the standard thin film based SPR instruments. ${ }^{17,18}$ The near field decay length of nanoparticles is at least 1 order of magnitude smaller than the exponentially decaying evanescent field length in thin film SPR; in other words, LSPR is more focused on the molecular scale interactions, which take place in the near vicinity of the particle surface. ${ }^{19}$ The near field intensity and its decay around the particles depend on the size, shape, and material properties of the nanostructures. ${ }^{20,21}$ Coupling and interparticle distances also play a major role in near field intensity and thus sensitivity enhancement. ${ }^{22,23}$

All of the listed aspects should be considered when selecting a nanofabrication method for LSPR sensor construction, which usually requires compromises. Control over the particles' size, shape, and distribution in a sufficiently large surface area (several $\mathrm{cm}^{2}$ ), preferably with a cheap and reproducible technology, could be considered optimal. With electron beam $^{24}$ or ion beam ${ }^{25}$ lithography it is possible to control the size and distribution of the nanostructures, resulting in high sensitivity, ${ }^{26}$ but patterning large surface areas is too expensive with this method. This is also true for nanoimprint lithography (NIL), where the hard masks are usually prepared with these technologies. ${ }^{27-29}$ Colloidal lithography ${ }^{30}$ and holemask colloidal lithography (HCL) ${ }^{11}$ are often used to pattern somewhat larger surface areas; however, there are some limitations regarding the size/shape of the fabricated structures, resulting in mediocre/small surface coverage and thus sensitivity. ${ }^{31,32}$ Precise control over the size and shape could be achieved through the colloidal synthesis of the nanoparticles. ${ }^{33}$ Here, the challenge is the subsequent binding of the nanoparticles to a substrate (through silanization ${ }^{34}$ or thiol chemistry $\left.{ }^{35}\right)$; the control over the distribution of the nanoparticle array is limited, and the uncoupled spherical nanoparticles usually have lower molecular sensitivities. ${ }^{2,36,37}$ Thermal annealing of a previously deposited thin film on glass or silicon is a simple technique to produce nanoislands, ${ }^{38}$ also combined with subsequent etching of the substrate to produce nanomushrooms, ${ }^{39,40}$ but the control over the arrangement is limited; ${ }^{39}$ because gold does not adhere well with $\mathrm{SiO}_{2}$, fluidic environments can remove the NPS from the surface. Drawbacks of the listed technologies which enable extra high sensitivities are either the small fabrication area $\left(\mathrm{EBL}^{26}\right)$ or the inhomogeneous surface. ${ }^{41} \mathrm{~A}$ recently introduced reversal nanoimprint lithography excelled in most of these aspects, with high sensitivities in the NIR range. ${ }^{42}$

Our proposed method (illustrated in Figure 1) is based on the controlled, template-assisted solid-state dewetting synthesis of nanoparticles and their transfer to a polymer; namely, epoxy support has the following distinct advantages compared to other technologies: (1) Controlled synthesis: the particle size and interparticle distance can be precisely controlled in a fixed hexagonal distribution, and thus the plasmonic absorption peak (and sensitivity) can be fine-tuned for individual applications. Besides plasmonic sensing, the absorption peak should be tuned for surface-enhanced Raman scattering (SERS) applications as well, where the relation between the resonance peak of the substrate and the excitation wavelength defined by the laser has an effect on the SERS enhancement. ${ }^{38,43}$ (2) Large scale fabrication: the lateral size of the substrate is not limited, sensors with several $\mathrm{cm}^{2}$ surface area can be easily prepared, and the nanoparticle size/distribution is homogeneous on the whole surface. Such large sensor areas are required for LSPR imaging (LSPRi) applications ${ }^{12}$ and also beneficial for SERS. ${ }^{44,4}$ (3) Robustness: the prepared nanocomposite-gold nanoparticle arrangement on fixed on epoxy pillars-is completely stable; there, is no particle removal exposed to fluidic environments. The surface of the gold can be cleaned multiple times with low-power $\mathrm{O}_{2}$ plasma without any significant drop in sensitivity. 


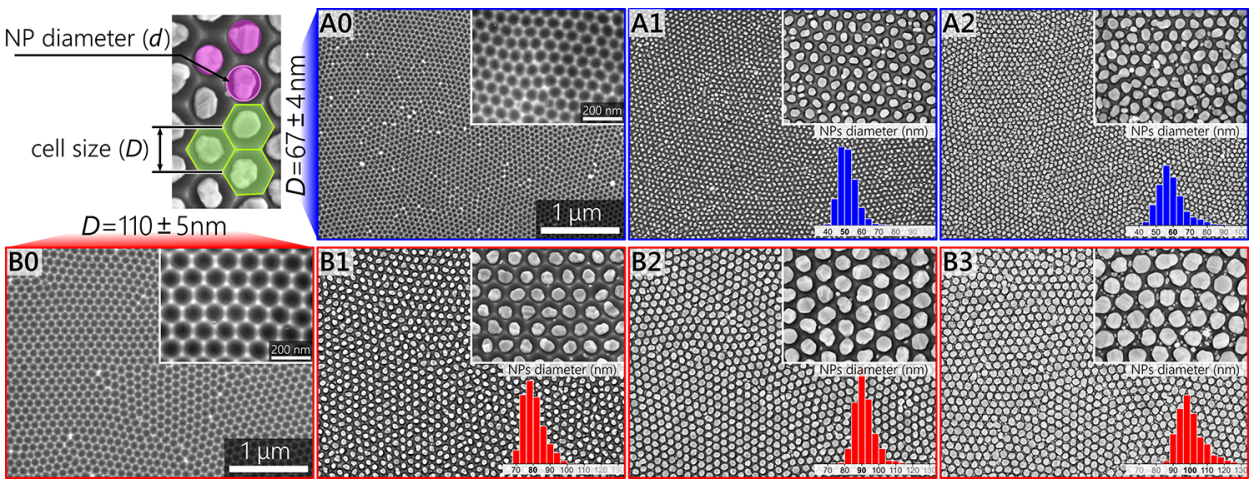

Figure 2. SEM images illustrating the control over the nanoparticle arrangement and sizes on two types of nanobowled $\mathrm{Al}$ templates formed by anodization at $25 \mathrm{~V}$ in sulfuric acid with cell sizes $D=67 \pm 4 \mathrm{~nm}$ (A type) and at $40 \mathrm{~V}$ in oxalic acid with $D=110 \pm 5 \mathrm{~nm}$ (B type). The size distributions $(d)$ of particles are the following: $51 \pm 5 \mathrm{~nm}(\mathrm{~A} 1), 60 \pm 7 \mathrm{~nm}(\mathrm{~A} 2), 79 \pm 6 \mathrm{~nm}(\mathrm{~B} 1), 92 \pm 6 \mathrm{~nm}(\mathrm{~B} 2)$, and $102 \pm 9 \mathrm{~nm}(\mathrm{~B} 3)$.

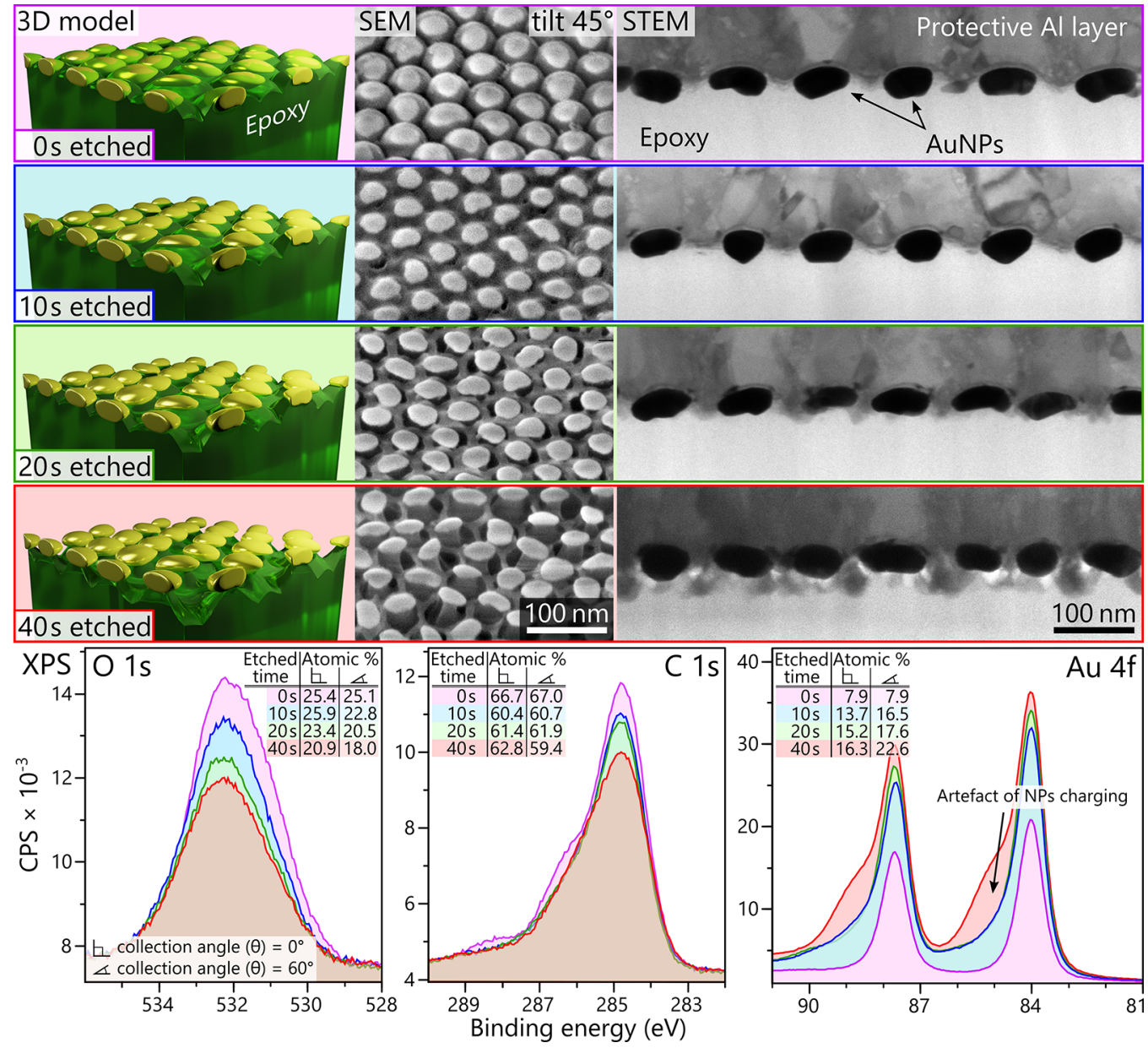

Figure 3. Illustration and the effect of selective epoxy etching on B1 type samples. Top row, left: $3 \mathrm{D}$ models. Middle: tilted (45 ${ }^{\circ}$ SEM views. Right: STEM cross-sectional images (bright mode). Etching times from top to bottom: 0, 10, 20, and 40 s. Bottom graphs: detailed XPS spectra of $\mathrm{O} 1 \mathrm{~s}, \mathrm{C} 1 \mathrm{~s}$, and $\mathrm{Au} 4 \mathrm{f}$ peaks; collection angle $(\theta)=60^{\circ}$. The tables show the estimated atomic concentrations for both standard $\left(\theta=0^{\circ}\right)$ and tilted $\left(\theta=60^{\circ}\right)$ measurements.

It also has to be noted that- to the best of our knowledge except for the Ag/PET based nano-Lycurgus cup arrays of Gartia et al. ${ }^{41}$ - ours is one of the first surface Au-NP/polymer nanocomposite LSPR sensor successfully used for label-free DNA detection. Surface Au/Ag-NP/polymer nanocomposites were successfully utilized for other applications, ${ }^{46}$ for example as protein LSPR sensors. ${ }^{47,48}$

\section{EXPERIMENTAL SECTION}

2.1. Preparation of the Nanobowled Aluminum Template. High-purity Al foils (99.999\%, $250 \mu \mathrm{m}$ thick, tempered as-rolled, Goodfellow) were cut into $25 \mathrm{~mm} \times 50 \mathrm{~mm}$ samples that were mechanically polished, finishing with a $3 \mu \mathrm{m}$ suspension. After the mechanical polishing, the foils were ultrasonicated in acetone and deionized water (MilliPore, 18.2 M $\Omega$ ), dried, and annealed in vacuum $\left(\sim 4 \times 10^{-4} \mathrm{~Pa}\right)$ at $550{ }^{\circ} \mathrm{C}$ for $15 \mathrm{~h}$ with a heating ramp of $10^{\circ} \mathrm{C}$ $\mathrm{min}^{-1}$ and natural cooling of $\sim 6 \mathrm{~h}$. One side of the Al foils were then 
electrochemically polished in a mixture $\left(0.6 \mathrm{dm}^{3}\right)$ of perchloric acid $(70 \% \mathrm{w} / \mathrm{w})$ and ethanol $(96 \% \mathrm{w} / \mathrm{w})$ with a volume ratio of $1: 4$ at 0 ${ }^{\circ} \mathrm{C}$. The electrochemical polishing were performed potentiostatically, in a two-electrode setup with a stainless mesh as a cathode, at $20 \mathrm{~V}$ for 1-2 min. After rinsing in deionized water and drying, $\mathrm{Al}$ foils were prepared for anodizing (Figure 1: phase 1).

The one-step anodizing was performed in the same setup as the electrochemical polishing by using oxalic acid solution $(0.3 \mathrm{M})$ at 7 ${ }^{\circ} \mathrm{C}$ with a potential of $40 \mathrm{~V}$ for $20 \mathrm{~h}$ or sulfuric acid solution $(0.3 \mathrm{M})$ at $0{ }^{\circ} \mathrm{C}$ with a potential of $25 \mathrm{~V}$ for $15 \mathrm{~h}$. To avoid unnecessary consumption of $\mathrm{Al}$ from unpolished side, the anodization was interrupted after the first $30 \mathrm{~min}$, the foil was cleaned and dried, and Kapton tape was applied on unpolished side to mask it from further anodizing. This resulted in an over $50 \mu \mathrm{m}$ thick porous anodic alumina (PAA) layer (Figure 1: phase 2) with hexagonally ordered cells of $67 \pm 4$ and $110 \pm 5 \mathrm{~nm}$ size for 25 and $40 \mathrm{~V}$, respectively.

To obtain the nanostructured (nanobowled) Al surface (Figure 1: phase 3), the PAA was selectively dissolved (from both sides) in a vigorously stirred mixture of phosphoric acid $(0.42 \mathrm{M})$ and chromium trioxide $(0.2 \mathrm{M})$ at $65^{\circ} \mathrm{C}$ for $2 \mathrm{~h}$, followed by thorough cleaning and ultrasonication in deionized water and methanol.

2.2. Formation of Gold Nanoparticle Arrangements. AuNPs were fabricated by utilizing the nanobowled $\mathrm{Al}$ template as substrate for controlled solid-state dewetting of a thin gold film (Figure 1: phase 4-5). First, a thin Au film was deposited by RF magnetron sputtering (BESTEC, magnetron sputtering system) with a rate of $0.035 \mathrm{~nm} \mathrm{~s}^{-1}$ (in an argon atmosphere of $10^{-1} \mathrm{~Pa}$ ), $200 \mathrm{~mm}$ distance, and $30^{\circ}$ angle between the $\mathrm{Al}$ template and the Au target (99.99\%, Kurt J. Lesker Company). The deposition rate was monitored in situ by a quartz crystal microbalance and ex situ by calibration sample profilometry measurements (discussed in detail in the Supporting Information S5). Afterward, the foils with Au films was thermally annealed on a hot plate at $300{ }^{\circ} \mathrm{C}$ for $5 \mathrm{~min}$ (discussed in the Supporting Information S3). Various distributions or sizes of AuNPs (example shown in Figure 2) were obtained by tuning the thickness of $\mathrm{Au}$ film and repeating these processes (deposition and annealing) for multiple times.

2.3. Transfer of Gold Nanoparticles. To utilize the fabricated AuNPs layers as a LSPR sensor element, they were transferred to an electrically nonconductive and optically transparent substrate (Figure 1: phase 6-7). A two-compound epoxy resin (Elan-tron EC 570 and W 363, weight ratio of 100:33) was cast over the AuNP layer in a thickness of a few millimeters and cured in an oven for $12 \mathrm{~h}$ at $50{ }^{\circ} \mathrm{C}$. Then, the Al substrate was dissolved in a hydrochloric acid (35\% w/ w) and copper(II) chloride (2 M) water solution. After that, the samples were immersed subsequently into iron(III) chloride $(2 \mathrm{M})$ and sodium hydroxide $(1 \mathrm{M})$ water solution for $10 \mathrm{~min}$ to remove copper and aluminum oxide residues, respectively.

2.4. Epoxy Substrate Etching. The epoxy substrate was dry etched in a PlasmaPro 80 RIE chamber (Oxford Instruments Plasma Technology), which uses capacitively coupled plasma (CCP). Prior to etching, samples were cut into square based pieces with $10 \mathrm{~mm}$ edge length and washed subsequently in deionized water, ethanol, and methanol, finished with drying under nitrogen steam. The RIE was performed for different time periods in an oxygen plasma at a pressure of $6.7 \mathrm{~Pa}$, power of $50 \mathrm{~W}$, and $\mathrm{O}_{2}$ flow rate of $50 \mathrm{sccm}$.

2.5. Characterization. Scanning electron microscopy (SEM) was performed with a high-resolution SEM (FEI Verios 460L) in secondary electron detector mode and an acceleration voltage of 5 $\mathrm{keV}$. Thin lamellae (thickness of $\sim 100 \mathrm{~nm}$ ) for transmission electron microscopy (TEM) were prepared by a dual-beam system (FIB-SEM Tescan LYRA3) (Figure 1) and a FEI Helios NanoLab 660 (Figure 3). Transmission electron microscopy (TEM) and scanning transmission microscopy (STEM) with energy-dispersive X-ray spectroscopy (EDS) in Figure 1 were performed with a Carl Zeiss LIBRA200FE (with a Bruker Quantax 200, $30 \mathrm{~mm}^{2}$ EDS detector). The STEM images in Figure 3 were obtained with a FEI Helios NanoLab 660 in bright field mode and operating voltage of $30 \mathrm{keV}$.

X-ray photoelectron spectroscopy (XPS) was conducted with a Kratos Analytical AXIS Supra instrument with a monochromatic Al
$\mathrm{K} \alpha$ X-ray source $(1486.6 \mathrm{eV})$ by using pass energy of $20 \mathrm{eV}$. The maximum lateral dimension of the analyzed area was $0.7 \mathrm{~mm}$. The spectra were acquired with a charge neutralization in overcompensated mode to avoid most of the charging effects. The calibration of binding energy (BE) scale was performed by shifting the hydrocarbon component $\mathrm{CHx}$ to $284.8 \mathrm{eV}$. The concentrations were estimated from peak intensities in the CasaXPS software (version 2.3.18) by using the Shirley-type background.

The optical spectroscopy measurements were performed either with an Avantes Avaspec 2048-4DT spectrometer and an Avantes Avalight DHS halogen light source (at BUTE) or with an UV-vis optical spectrometer (Ocean Optics JAZ 3-channel) with a tungsten halogen light source.

2.6. LSPR Sensor Tests. The bulk refractive index sensitivity of the plasmonic sensors was tested by changing the medium above the samples between air, deionized water, and a sucrose dilution series $(25 \%, 50 \%$, and $75 \%$ in deionized water). The sensor surface was illuminated in a circular area with a diameter of $8 \mathrm{~mm}$, and a glass microscope sheet was used to cover the dispersed media on the samples.

2.7. DNA Experiments. The same protocols were followed, which were used and tested in a previous work. ${ }^{49}$ The oligomers were purchased from Sigma-Aldrich (Germany), and the stock solutions were prepared by using $\mathrm{NaCl}(0.5 \mathrm{M})-\mathrm{Na}_{2} \mathrm{HPO}_{4}(0.05 \mathrm{M}), \mathrm{pH} 6.8$, buffer (termed running buffer, $\mathrm{RB}$, from now on). The base sequences of the probe and target ss-DNA, which form a specific sequence from the parasite Giardia lamblia (the $\beta$-giardin gene), ${ }^{50}$ are the following (from $5^{\prime}$ to $3^{\prime}$ ): Giardia_probe: CGTACATCTTCTTCCTTTTT[ThiC6]; Giardia_target: AGGAAGAAGATGTACGACCA. The probe and target ss-DNAs are both 20 bases long, and the complementary sequence in the target is 16 bases. As a negative control, the following 20 bases long noncomplementary DNA sequence was used: CTGTGTCGATCAGTTCTCCA. Prior to surface functionalization, the sensor surfaces were freshly cleaned with low-power $\mathrm{O}_{2}$ plasma by using a Diener Atto chamber at a pressure of $40 \mathrm{~Pa}$ at $20 \mathrm{~W}$ power for $15 \mathrm{~s}$. For probe immobilization the sensors surfaces were immersed into a solution of thiol modified ss-DNA ( $1 \mu \mathrm{M}$ Giardia_probe) for an overnight $(\sim 16 \mathrm{~h})$ incubation. The ionic strength of the buffer was varied between $0.5,0.75$, and $1 \mathrm{M}$ $\mathrm{NaCl}$, as indicated at the discussion of the results. After probe immobilization the surface of the sensor was thoroughly rinsed with the same buffer that was used for the immobilization. Subsequently, the whole sensor surface was passivated with 6-mercapto-1-hexanol (1 $\mathrm{mM}, \mathrm{MCH}$, in the same buffer) for $30 \mathrm{~min}$ to reduce nonspecific binding of probe-DNA on the gold surface. After $\mathrm{MCH}$ treatment, the sensor surface was rinsed again. Finally, the target ss-DNA (Giardia_target, in various concentrations between $1 \mathrm{nM}$ and 3 $\mu \mathrm{M})$ diluted in the same buffer as the immobilization solution was added. The hybridization time was $2 \mathrm{~h}$; after that, the surface was rinsed again with the corresponding buffer extensively. All optical spectroscopy measurements (on a bare sensors surface, after probeDNA immobilization, after $\mathrm{MCH}$ treatment, and after hybridization with target-DNA) were done in RB medium (after washing) as well, so the effect of DNA binding can be compared to the same baseline. The immobilization and hybridization steps were performed by drop coating the surface of the samples with the respective DNA solutions. The incubation was performed in a humidified, hermetically sealed dish to avoid the evaporation of the solutions. All experiments were performed at laboratory ambient temperatures $\left(22^{\circ} \mathrm{C}\right)$.

\section{RESULTS AND DISCUSSION}

3.1. Nanoparticle Arrangement Control. In the ideal case the solid-state dewetting of an $\mathrm{Au}$ thin film on the aluminum nanobowled template leads to the formation of one nanoparticle per a single bowl, with the volume corresponding to the dimple area and thickness of the deposited film. This process is primarily governed by the template's hexagonal protrusions; these sharp and uniform structures confine areas for NP growth. The driving force behind nanoparticle 
formation can be explained by the theory of surface energy minimization, previously explained on the same structures by Fan and others. ${ }^{51}$ Therefore, the most important parameters to control the NPs uniformity, distribution, and size are the template morphology and deposited layer thickness (and its morphology), as it was also investigated and demonstrated in our previous work, ${ }^{52}$ or other publications. ${ }^{51,53}$

In this work we focused on utilizing the aluminum nanobowled template, whose morphology is inherited from the PAA. However, the hexagonally self-ordered PAA structure can be achieved within a relatively narrow window of anodizing conditions. For the given electrolyte system there is an optimal anodizing potential which determines the PAA cell size and thus the nanobowl's diameter (proportional constant of $2.5 \mathrm{~nm}$ $\mathrm{V}^{-1}$ ). In this work, the most conventional processes were chosen: $0.3 \mathrm{M}$ sulfuric acid $(U=25 \mathrm{~V})$ and $0.3 \mathrm{M}$ oxalic acid $(U=40 \mathrm{~V})$, resulting in template morphologies shown in Figures 2(A0) and 2(B0), respectively. The images show defect-free domains whose lateral size is limited to only a several micrometers (tens of cells). ${ }^{54}$ Although this is a major cause of NP lattice defects, this could be considered as a common drawback of any self-ordering processes (for example, it also happens with self-ordering PS ball based techniques as well). ${ }^{55}$ Technologies that can overcome these issues (for example, soft imprinting) are either not applicable for this work or are very expensive for large surface area patterning (for example, e-beam lithography).

In the case of ideal dewetting, the $\mathrm{Al}$ template determines NPs arrangement (hexagonal) and interparticle distances (center to center) are given by the cell size. Although the size of NPs can be tuned by the thickness of the deposited $\mathrm{Au}$ film, it was experimentally observed that only a narrow range of thickness leads to an ideal dewetting process with respect to the $\mathrm{Al}$ template morphology (cell size). In our case it was experimentally established that the ideal thicknesses are approximately 6 and $8 \mathrm{~nm}$ for type A and type B templates (shown in Figure 2(A1,B1)), respectively. For smaller layer thicknesses more voids can be observed after annealing, especially at the side of the protrusions, which causes undesirable separation and formation of NPs independently from the nanobowled template (shown in Figure S1: $6 \mathrm{~nm}$ ). On the other side, increasing the thickness above the optimum leads to incomplete NPs separation: the NPs can remain connected through bridges over sharp template protrusions. Other groups reported similar observations regarding the dewetting process on different substrates. ${ }^{55-57}$ To match the arrangement of the NPs with the pattern defined by the template, it is important to control not only the deposited film thickness but also the film morphology (explained in more detail in the Supporting Information S1-S3). The morphology of the film may vary based on the selected deposition technique and its parameters. Here vacuum sputtering was selected since it yields smoother films compared to vacuum evaporation (as demonstrated in Figure S5), but the in-depth investigation of other deposition techniques was not the aim of our current work.

However, as seen in Figure 2(A1,B1) with these optimal initial layer thicknesses the resulting NPs have undesirably large interparticle distances which would not yield substantial sensitivity enhancement by plasmon coupling. To decrease the distance between nanoparticles and at the same time increase their size, the deposition and annealing processes were repeated multiple times. The examples in Figure 2 were prepared by sequential deposition and annealing, where the deposited layer thicknesses were the following: (A2) $6 \mathrm{~nm}+5$ $\mathrm{nm}$, (B2) $8 \mathrm{~nm}+7 \mathrm{~nm}$, and (B3) $8 \mathrm{~nm}+7 \mathrm{~nm}+5.5 \mathrm{~nm}$. An analogous method is present by Kang and others by using a template-less dewetting technique. ${ }^{58}$ As the result of these procedures, it is possible to achieve well-ordered, uniform, and closely packed NP layers with gap distances under $10 \mathrm{~nm}$ (Figure 2(A2,B3)). If the separation between the particles is sufficiently small, interparticle plasmon coupling will occur, which could lead to a significant increase in the near field intensity in the gap and also to a significant increase in LSPR bulk refractive index sensitivity (or SERS enhancement in other applications). ${ }^{38}$ Efforts to further decrease the interparticle gap resulted in predominant defect formation and merging of the NPs. Compared to the first layer, tuning the thickness for subsequent films is even more challenging, which leads to a compromise including possible NP merging and formation of small, secondary NPs (as illustrated in Figure S4). This NP merging is not desirable, since the change in the particle shape would add other components into the plasmonic absorbance spectrum of the arrangement, causing red-shift and widening of the absorbance peak. Such tightly packed nanoparticles, synthesized by a distantly similar technique utilizing porous alumina templates, were proved to be sufficiently sensitive for molecular scale sensing to detect biomarkers. $^{59}$

3.2. Nanoparticle Transfer to Epoxy and Nanocomposite Stability. To use the synthesized AuNP arrangements as plasmonic biosensors (working in fluidic environments), it is necessary to fix the NPs onto a different substrate. A general problem with the solid state dewetting based NP synthesis methods is that the NPs do not adhere well to the substrate used for synthesis and can be washed away easily. Also, in this case the NPs are electrically coupled to the aluminum substrate, which hinders their plasmon resonance. Third, having a transparent substrate under the AuNP arrangement is beneficial, for in this case the sensors can be used in a simpler transmission based optical setup.

For these practical reasons the NPs were transferred after synthesis onto an electrically nonconductive and optically transparent substrate via simple polymer casting. Although several substrate materials were tested-including PDMS and PMMA-epoxy was found to be the most suitable candidate for this purpose unanimously. The main reason for this is that after the transfer of the NPs a subsequent polymer etching step is required to remove the casted polymer from the surface of the NPs. This etching can be easily performed in the case of epoxy with simple $\mathrm{O}_{2}$ plasma, while it requires more aggressive etchants and complex procedures for sturdier polymers, such as PDMS. On the other hand, we observed that thermoplastics (like PMMA) are not suitable for this kind of plasma etching due to their low glass transition and melting temperatures. These temperatures can be locally reached due to the heating of NPs, caused by the microwave irradiation. In comparison, thermoset epoxy is much more stable in this regards. Today $\mathrm{O}_{2}$ plasma is a commonly used cleaning protocol for sensor surfaces; thus, the selective etching of epoxy with $\mathrm{O}_{2}$ plasma can be considered compatible with standard laboratory protocols.

Figure 3 gives a comprehensive illustration regarding the selective etching of epoxy with $\mathrm{O}_{2}$ plasma. Directly after polymer casting the transferred NPs are partially covered with a thin epoxy layer, as can be clearly seen on the SEM images. 


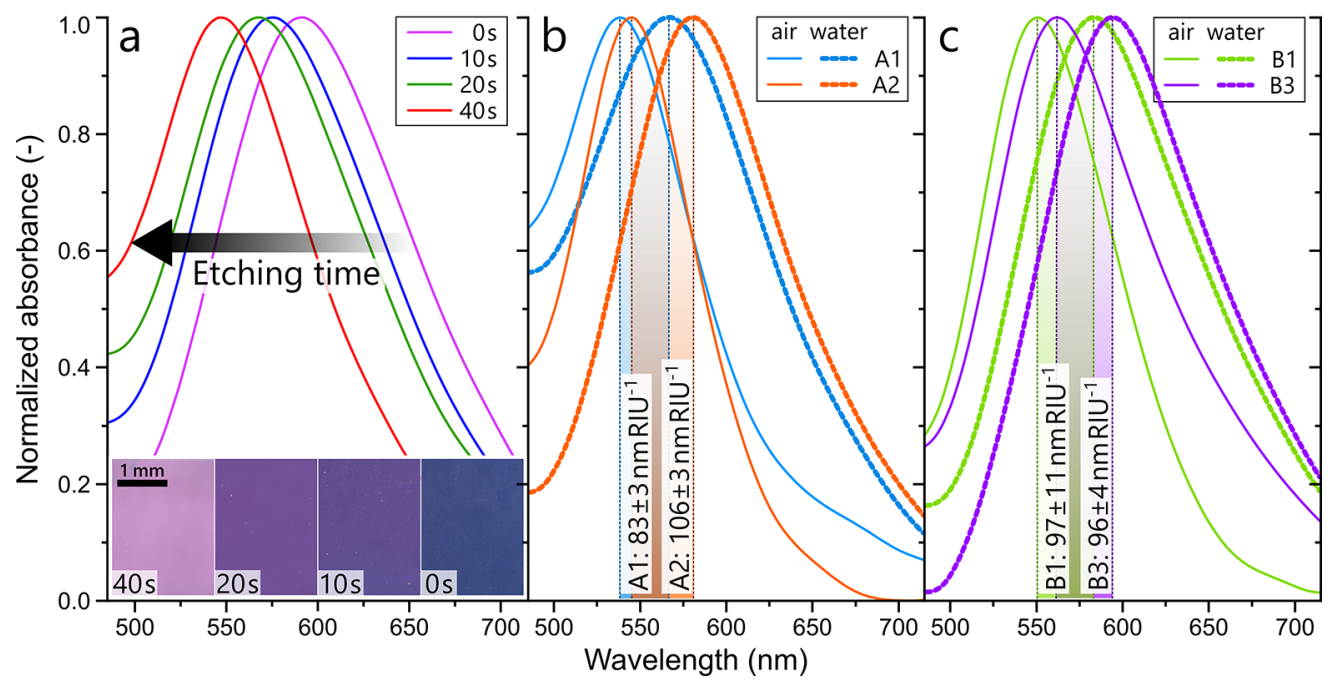

Figure 4. Normalized absorbance spectra of (a) A1 type nanocomposites after different times of selective epoxy etching with $\mathrm{O}_{2}$ plasma, measured in air (data corresponding to Figure 3) with inset of optical microscopy images (transmission) of corresponding samples; (b) A1 and A2 type samples after $30 \mathrm{~s}$ selective etching measured in air and in water; (c) B1 and B3 type samples after $30 \mathrm{~s}$ selective etching measured in air and in water, respectively.
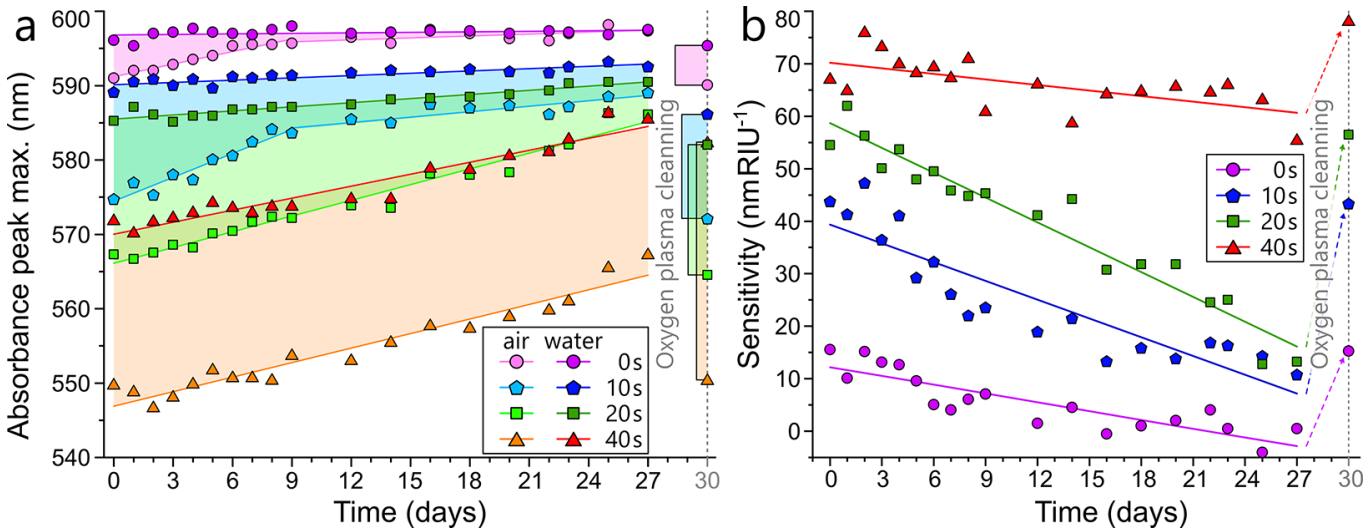

Figure 5. (a) Position of the LSPR absorbance peak maxima of the etched Al type nanocomposite samples measured in air and in water, respectively. (b) Calculated bulk refractive index sensitivities of the same sensors. The values on the right side of the graphs represent the condition of the samples after cleaning them with low-power $\mathrm{O}_{2}$ plasma after 30 days. The samples correspond to the ones presented in Figure 3 and Figure 4a.

This is also confirmed by the color of the samples (Figure 4) and the very small bulk refractive index sensitivities, measured directly after the transfer (around $15 \mathrm{~nm} \mathrm{RIU}^{-1}$, Figure 5). Etching the epoxy samples in $\mathrm{O}_{2}$ plasma (at a pressure of 6.7 $\mathrm{Pa}$, power of $50 \mathrm{~W}$, and $\mathrm{O}_{2}$ flow rate of $50 \mathrm{sccm}$ ) for 10, 20, and $40 \mathrm{~s}$ gradually removes the epoxy from between the particles (Figure 3), as confirmed by the SEM and STEM images. Because the AuNPs mask the underlying areas of epoxy from etching, the resulting structures will resemble mushroom-like shapes, with gradually narrowing epoxy pillars holding the NPs on top. The 3D models of Figure 3 were reconstructed based on the SEM and STEM images. It is also worth mentioning that judging by the cross-sectional STEM images the shape of the AuNPs is closer to flattened disks (resembling red blood cells) than spheres. With such flattened shapes interparticle interactions and coupling are expected to be stronger in the lateral plane compared to spherical NPs. ${ }^{60}$

The successful selective removal of the epoxy from the top and between the particles is also confirmed by XPS measurements, presented in Figure 3. Longer etching times gradually decrease the atomic percentage of oxygen and carbon on the surface (based on the $\mathrm{O} 1 \mathrm{~s}$ and $\mathrm{C} 1 \mathrm{~s}$ peaks, respectively), while at the same time increasing the atomic percentage of gold ( $\mathrm{Au} 4 \mathrm{f}$ peaks). Parallel optical spectrophotometry measurements were done on the same samples (from the B1 line). The normalized absorbance spectra of Figure $4 \mathrm{a}$ also confirm the successful removal of the epoxy. The absorbance peak measured in air decreased from the initial $590 \mathrm{~nm}$ to $575,567.5$, and $547 \mathrm{~nm}$ after 10, 20, and $40 \mathrm{~s}$ selective etching, respectively (Figure $4 \mathrm{a}$ ). The changes in the color of the samples upon etching are visible to the naked eye as well (inset of Figure 4a). As can be seen in Figure 5, this change goes hand in hand with increasing bulk RI sensitivity, from the initial $15 \mathrm{~nm} \mathrm{RIU}{ }^{-1}$ to around $80 \mathrm{~nm} \mathrm{RIU}^{-1}$, for this particular B1 type sample. Because for other applications, like SERS, the position of the LSPR peak alone could be important, it has to be mentioned that by varying the particle size, interparticle distance, and epoxy etching, it was possible to tune the plasmonic peak of the sensors elements between 535 and $625 \mathrm{~nm}$, measured in air.

The best achievable RI sensitivities were found to be $83 \pm 3$ $\mathrm{nm} \mathrm{RIU}{ }^{-1}$ for $\mathrm{A} 1,106 \pm 3 \mathrm{~nm} \mathrm{RIU}{ }^{-1}$ for $\mathrm{A} 2,97 \pm 11 \mathrm{~nm}$ 

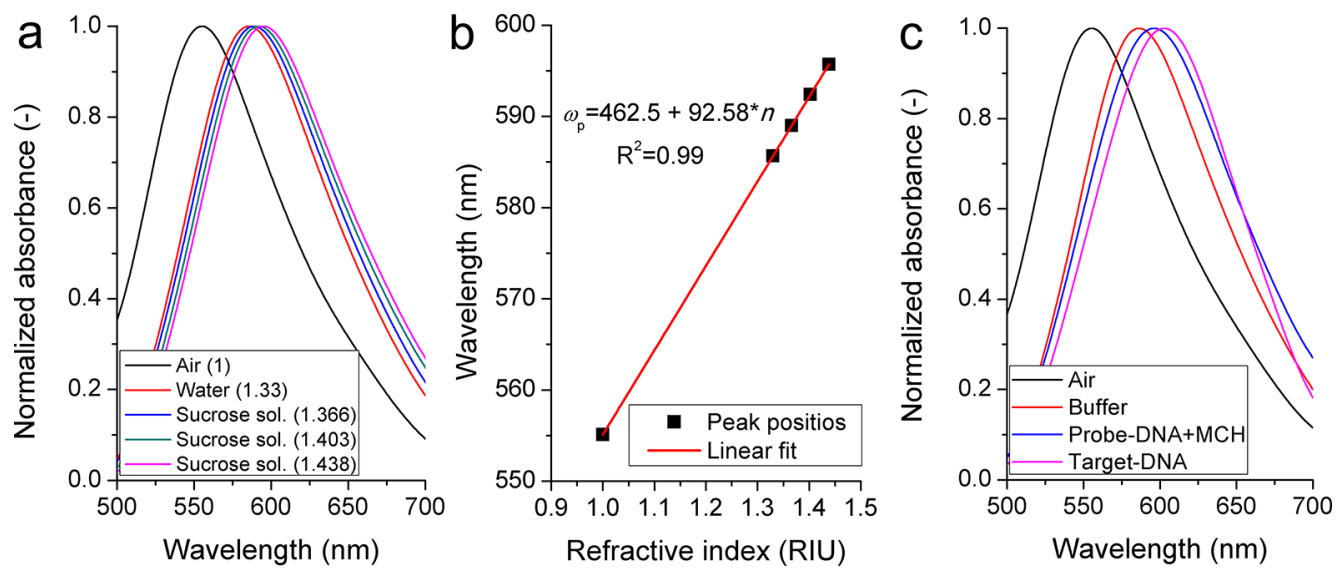

Figure 6. (a) Normalized absorbance spectra of a B3 type nanocomposite sample, measured in different media (sucrose solutions). (b) Linear regression of the LSPR peak maxima shown in (a). (c) Normalized absorbance spectra measured in different phases of probe-DNA immobilization and target-DNA hybridization, measured on a $\mathrm{B} 3$ type nanocomposite, by using a $0.75 \mathrm{M} \mathrm{NaCl}-50 \mathrm{mM} \mathrm{Na}_{2} \mathrm{HPO}_{4}$ buffer.
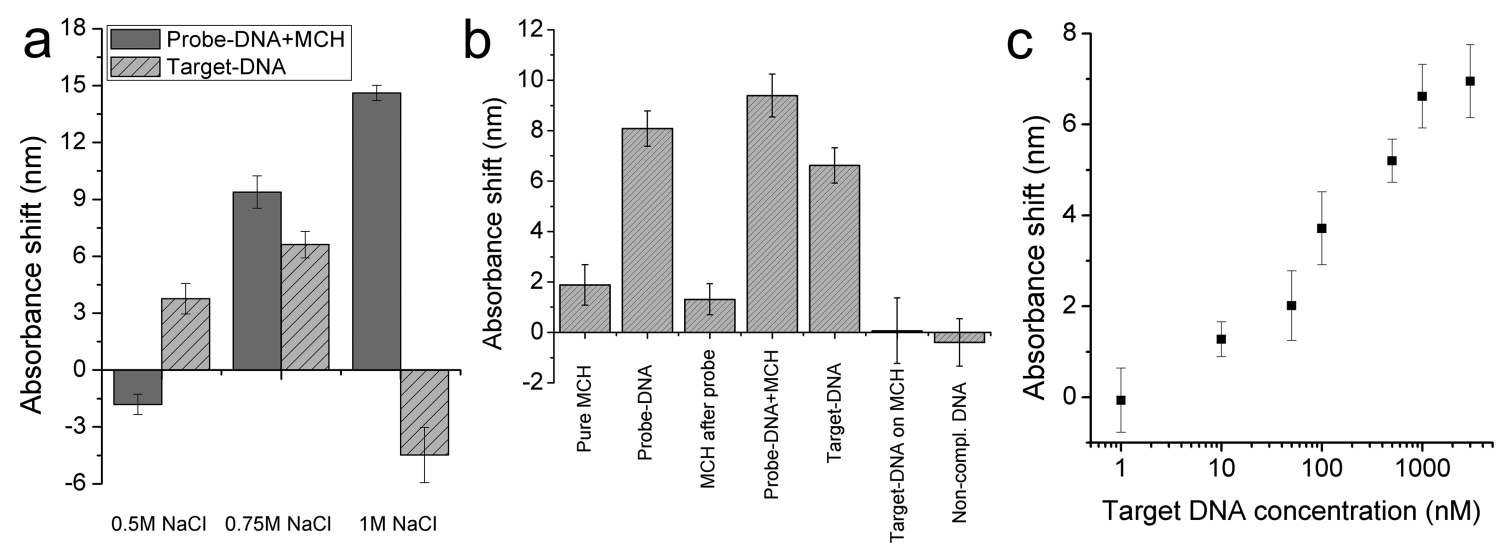

Figure 7. (a) Absolute LSPR absorbance shift measured after DNA immobilization and subsequent DNA hybridization by using buffers with different ionic strengths on the B3 type nanocomposite. (b) Results of control experiments (performed in a buffer with $0.75 \mathrm{M}$ ionic strength, B3 type composite) aiming to distinguish between the signal contribution of $\mathrm{MCH}$ and probe-DNA during immobilization and also negative controls with noncomplementary DNA. (c) Calibration curve of the B3 type nanocomposite. All data are an average of 4-5 measurements.

$\mathrm{RIU}^{-1}$ for $\mathrm{B} 1$, and $96 \pm 4 \mathrm{~nm} \mathrm{RIU}{ }^{-1}$ for the $\mathrm{B} 3$ sample, all after $30 \mathrm{~s}$ etching time (illustrated in Figures $4 \mathrm{~b}$ and $4 \mathrm{c}$ ). It has to be noted that overetching these samples in $\mathrm{O}_{2}$ plasma could destabilize the AuNP arrangement's integrity by narrowing the epoxy pillars below a critical point, resulting in NP removal during washing, leading to decreased sensitivity. The $30 \mathrm{~s} \mathrm{O}_{2}$ plasma etching always resulted in stable samples, with reproducible spectra and reversible changes after multiple steps of washing and drying. Adhesion tests were also performed on the etched samples, and the NPs could not be removed by the classic Scotch tape method (see Supporting Information S7).

The stability (robustness) and cleanability of the fabricated plasmonic sensors are of outmost importance since before the immobilization of receptor molecules the surface of the gold has to be cleaned sufficiently. For this, this long-term stability of the sensors was tested. Figure 5 shows the absorbance peak maxima (in air and water, Figure 5a) and respective bulk RI sensitivities (Figure 5b) monitored for 27 consecutive days, measured on the same samples as in Figures 3 and 4a. Upon storage at normal office ambient conditions the bulk RI sensitivity of the sensors gradually decreased with the elapsed time, which is not surprising, knowing that the surface of gold can easily be contaminated by numerous ambient agents. ${ }^{61}$
Despite the significant drop in sensitivity with time, the samples could be easily regenerated with short, low-power $\mathrm{O}_{2}$ plasma cleaning $(20 \mathrm{~W}$ power at $0.4 \mathrm{mbar}$ for $15 \mathrm{~s})$, to retain their initial sensitivities. Other long-term tests performed with multiple cleaning steps demonstrated that the sensors could be effectively cleaned with such low-power $\mathrm{O}_{2}$ plasma several times (3-5), without any significant drop in sensitivity. The robustness and cleanability of the fabricated sensors elements thus enable their application as LSPR biosensors.

3.3. Detection of DNA Hybridization. To test the fabricated epoxy-Au nanocomposites as LSPR sensors for DNA hybridization detection, a 20 bp long specific sequence from the parasite Giardia lamblia (the $\beta$-giardin gene) was used. This particular sequence and probe-target DNA pair were extensively tested in a previous work with both an SPR and a capacitive sensor. ${ }^{49}$ Here, the exact same probe immobilization and target hybridization protocols were used. For these experiments we only used nanocomposites from the B3 batch. Figures $6 a$ and $6 \mathrm{~b}$ present bulk refractive index calibration results for one of the samples, performed with a dilution series of sucrose dissolved in water. The LSPR sensor has a linear response in the relevant refractive index range of 1-1.44 RIU, with a bulk RI sensitivity of $92.58 \mathrm{~nm} \mathrm{RIU}{ }^{-1}$. 
Figure $6 \mathrm{c}$ presents the resulting absolute shift of the absorbance spectra after Giardia_probe $+\mathrm{MCH}$ immobilization (overnight from $1 \mu \mathrm{M}$ solution) and the subsequent hybridization with $1 \mu \mathrm{M}$ Giardia_target for $2 \mathrm{~h}$. The spectra were always measured in the specified running buffer. The shifts are defined between the subsequent phases; for example, probe immobilization is compared to the spectra measured in empty buffer prior immobilization, while the shift caused by hybridization is compared to the spectra measured after immobilization. Buffers with three different ionic strengths were investigated, namely $0.5,0.75$, and $1 \mathrm{M}$; the resulting absorbance shifts are given in Figure 7a. The first set of experiments were performed in the same buffer which was used in the mentioned reference, ${ }^{49}$ namely $0.5 \mathrm{M} \mathrm{NaCl}-50 \mathrm{mM}$ $\mathrm{Na}_{2} \mathrm{HPO}_{4}, \mathrm{pH}$ 6.8. In this buffer a small, but reproducible, blue-shift $(1.8 \pm 0.5 \mathrm{~nm})$ of the spectra was observed after probe-DNA immobilization and a subsequent $3.8 \pm 0.8 \mathrm{~nm}$ red-shift after the hybridization with the target-DNA. Although it is known that the presence of DNA on the nanoparticle's surface increases the effective refractive index in the surrounding media and causes a red-shift in absorbance, such a blue-shift upon DNA binding is not entirely unexpected or unprecedented in LSPR systems. Roether et al. also measured a 2-3 nm blue-shift upon DNA immobilization, ${ }^{39}$ while others explained their observed blue-shifts with plasmon uncoupling between particles. ${ }^{13,48}$ In our nanoparticle arrangement (B3 type) the average interparticle gap between the nanoparticles is around $10 \mathrm{~nm}$, while due to the irregular shape of the particles it can sometimes be below $5 \mathrm{~nm}$ in hot spots. Because the length of the Giardia_probe is around $7 \mathrm{~nm}$, it is possible that the repulsion between the negatively charged DNA strands in these gaps causes the particles to shift out of the coupling plane (by slightly bending the epoxy pillars), resulting in plasmonic uncoupling and the observed blue-shift in the spectra. To test this theory, the measurements were repeated in buffers with increased ionic strength $(0.75$ and $1 \mathrm{M} \mathrm{NaCl}$; both with 50 $\left.\mathrm{mm} \mathrm{Na}_{2} \mathrm{HPO}_{4}\right)$. Higher ionic strength was proven to be effective in decreasing the repulsion between the DNA strands by screening the charges of their sugar-phosphate backbone and thus decreasing their Debye length, ${ }^{62}$ resulting in more tightly packed DNA layers. ${ }^{63} \mathrm{NaCl}$ in high concentration (such as $1 \mathrm{M}$ ) is particularly used for this purpose. ${ }^{64,65}$

As can be seen in Figure 7a, in higher ionic buffers the immobilization of Giardia_probe resulted in a red-shifts of 9.4 \pm 0.8 and $14.6 \pm 0.4 \mathrm{~nm}$ in buffers with 0.75 and $1 \mathrm{M}$ ionic strength, respectively. For the $0.75 \mathrm{M}$ buffer the $6.6 \pm 0.7 \mathrm{~nm}$ red-shift signal resulting from target-DNA hybridization was also significantly higher compared to the $0.5 \mathrm{M}$ buffer. In the case of the buffer with $1 \mathrm{M}$ ionic strength the hybridization resulted in a blue-shift of $4.5 \pm 1.5 \mathrm{~nm}$, but this time this can be associated with damaged NP integrity. During the washing step after target-hybridization some AuNPs were visibly washed away from the surface. This phenomenon never happened with buffers of lower ionic strength (and as it was discussed in section 3.2 the nanocomposite was found to be quite robust with stable NPs), while it was reproducible in $1 \mathrm{M}$ ionic strength; thus, it can be accounted for the instability caused by the too tightly packed DNA molecules. This phenomenon is investigated in more detail in Supporting Information S7. Figure 6c presents normalized absorption spectra measured in the $0.75 \mathrm{M}$ buffer, illustrating the $9.4 \pm 0.8$ $\mathrm{nm}$ red-shift upon immobilization of probe (compared to empty buffer) and subsequent $6.6 \pm 0.7 \mathrm{~nm}$ red-shift upon hybridization with the target.

Figure $7 \mathrm{~b}$ presents the result of control experiments-all performed in a buffer with $0.75 \mathrm{M}$ ionic strength. The deposition of a pure $\mathrm{MCH}$ monolayer resulted in a $1.88 \pm 0.8$ $\mathrm{nm}$ shift, while a pure probe-DNA layer in $8.08 \pm 0.7 \mathrm{~nm}$. Adding the $\mathrm{MCH}$ after the probe results in a smaller $1.31 \pm 0.6$ $\mathrm{nm}$ shift compared to the pure $\mathrm{MCH}$ monolayer. Based on these values, the probe surface density was roughly estimated to be around $(2-5) \times 10^{12}$ molecules $\mathrm{cm}^{-2}$ (details of the calculations are presented in the Supporting Information S9). Upon comparison of the signals of probe-DNA $(8.08 \pm 0.7$ $\mathrm{nm})$ and subsequent target-DNA hybridization $(6.62 \pm 0.7$ $\mathrm{nm})$, the signal ratio is around $80 \%$, which corresponds well with the work of Gong et al., who predicted a hybridization efficiency between $70-90 \%$ for buffers between $0.33-1 \mathrm{M}$ on a probe coverage between $(2-8) \times 10^{12}$ molecules $\mathrm{cm}^{-2}$. ${ }^{63}$

The calibration curve for a B3 type nanocomposite is presented in Figure $7 \mathrm{c}$. The target-DNA signal starts to saturate around $1 \mu \mathrm{M}$ concentration, and the characteristic is linear (as a function of a logarithmic target concentration) between $10 \mathrm{nM}$ and $1 \mu \mathrm{M}$, mostly consistent with previous works on such SPR/LSPR DNA biosensors. ${ }^{36,49,66}$ It has to be noted that the measured variation of the signal (between $\pm 0.3-0.8 \mathrm{~nm}$ ) originates from the variation between samples/ sample areas, since the sample is removed/replaced in the spectrometer in each step of the experiment. By integrating the LSPR chip into a microfluidic setup and monitoring a fixed area constantly, we could significantly reduce these errors. The standard deviation of the blank signal (measured by monitoring the same sensor area in a blank buffer for 10 $\min$ ) is around $0.1 \mathrm{~nm}$. Based on this, the LOD (defined as the signal from the blank sample plus 3 times the standard deviation of the signal from the blank sample) is around $5 \mathrm{nM}$. The same probe-target DNA system was measured previously with a commercial SPR instrument, resulting in sub-nanomolar detection limit. ${ }^{49}$ However, this detection limit and maximum signal response for a 20 bases long target are comparable and even better than several LSPR sensor solutions which were previously presented for label-free DNA detection. ${ }^{32,36,37,39}$

\section{CONCLUSIONS}

The fabrication technology and plasmonic sensor application of an AuNP-epoxy based surface nanocomposites were presented. It was extensively demonstrated that with this versatile, nanopatterned template based fabrication technology the large scale production of robust plasmonic sensors with tunable properties is possible. The main advantage of the proposed fabrication technology is the large (several $\mathrm{cm}^{2}$ ) surface area, in which the nanoparticle size/distribution is homogeneous and also tunable with the technological properties. Other strengths of the nanocomposite are the stability of the arranged AuNPs on the epoxy pillars in fluidic environments and also their repeated cleanability with reproducible sensitivities. The LSPR sensors were successfully used for the label-free detection of a $20 \mathrm{bp}$ long DNA molecule, making it one of the first NP-polymer surface nanocomposite sensors ever demonstrated for the plasmonic detection of DNA. 


\section{ASSOCIATED CONTENT}

\section{(1) Supporting Information}

The Supporting Information is available free of charge at https://pubs.acs.org/doi/10.1021/acsami.9b20907.

S1: solid state dewetting of Au films with various thicknesses on the nanobowled templates; S2: influence of the native aluminum oxide on the morphology of the deposited thin film; S3: influence of the annealing temperature on the resulting NP layers; S4: repeated $\mathrm{Au}$ thin film deposition and annealing on the nanobowled templates; S5: thickness estimation of gold thin films; S6: estimation of the nanoparticles' size and distribution; S7: adhesion tests; S8: structural instability after DNA immobilization in high ( $1 \mathrm{M})$ ionic strength buffer; S9: assessment of probe-DNA coverage (PDF)

\section{AUTHOR INFORMATION}

\section{Corresponding Author}

Attila Bonyár - Budapest University of Technology and Economics, Budapest, Hungary; (1) orcid.org/0000-00026976-7846; Email: bonyar@ett.bme.hu

\section{Other Author \\ Tomás Lednický - Brno University of Technology, Brno, Czech Republic}

Complete contact information is available at:

https://pubs.acs.org/10.1021/acsami.9b20907

\section{Author Contributions}

The manuscript was written through contributions of all authors. All authors have given approval to the final version of the manuscript. The detailed contributions of the authors are the following: Tomáš Lednický: PhD student, developed and optimized the nanocomposite fabrication technology, performed and evaluated SEM, STEM, XPS, and optical spectroscopy measurements, and wrote parts of the paper. Attila Bonyár: $\mathrm{PhD}$, associate professor, coordinated the development of the plasmonic sensor, performed the DNA experiments, performed and evaluated optical spectroscopy measurements, and wrote parts of the paper.

\section{Funding}

Part of the work was performed with the support of CEITEC Nano Research Infrastructure (ID LM2015041, MEYS CR, 2016-2019), CEITEC Brno University of Technology. The research reported in this paper was partially supported by the Higher Education Excellence Program of the Ministry of Human Capacities in the frame of Nanotechnology and Materials Science (BME FIKP-NAT) and also Biotechnology (BME-FIKP-BIO) research areas of Budapest University of Technology and Economics. Tomáš Lednický acknowledges the financial support of GACR Project GA16-11140S from the Czech Republic. The support of the Hungarian Electronic Information Service National Programme (EISZ) is also acknowledged.

\section{Notes}

The authors declare no competing financial interest.

\section{ACKNOWLEDGMENTS}

Attila Bonyár is grateful for the support of the Janos Bolyai Research Scholarship of the Hungarian Academy of Sciences.
We thank Jan Michalička (CEITEC BUT) for lamella preparation and TEM/STEM/EDS analysis.

\section{REFERENCES}

(1) Liedberg, B.; Nylander, C.; Lunström, I. Surface Plasmon Resonance for Gas Detection and Biosensing. Sens. Actuators 1983, 4 (C), 299-304.

(2) Nguyen, H.; Park, J.; Kang, S.; Kim, M. Surface Plasmon Resonance: A Versatile Technique for Biosensor Applications. Sensors 2015, 15 (5), 10481-10510.

(3) Homola, J. Surface Plasmon Resonance Sensors for Detection of Chemical and Biological Species. Chem. Rev. 2008, 108 (2), 462-493.

(4) Wong, C. L.; Olivo, M. Surface Plasmon Resonance Imaging Sensors: A Review. Plasmonics 2014, 9 (4), 809-824.

(5) Chinowsky, T. M.; Quinn, J. G.; Bartholomew, D. U.; Kaiser, R.; Elkind, J. L. Performance of the Spreeta 2000 Integrated Surface Plasmon Resonance Affinity Sensor. Sens. Actuators, B 2003, 91 (13), 266-274.

(6) Chinowsky, T. M.; Soelberg, S. D.; Baker, P.; Swanson, N. R.; Kauffman, P.; Mactutis, A.; Grow, M. S.; Atmar, R.; Yee, S. S.; Furlong, C. E. Portable 24-Analyte Surface Plasmon Resonance Instruments for Rapid, Versatile Biodetection. Biosens. Bioelectron. 2007, 22 (9-10), 2268-2275.

(7) Naimushin, A. N.; Soelberg, S. D.; Bartholomew, D. U.; Elkind, J. L.; Furlong, C. E. A Portable Surface Plasmon Resonance (SPR) Sensor System with Temperature Regulation. Sens. Actuators, B 2003, 96 (1-2), 253-260.

(8) Feltis, B. N.; Sexton, B. A.; Glenn, F. L.; Best, M. J.; Wilkins, M.; Davis, T. J. A Hand-Held Surface Plasmon Resonance Biosensor for the Detection of Ricin and Other Biological Agents. Biosens. Bioelectron. 2008, 23 (7), 1131-1136.

(9) Nanoplasmonic Sensors; Dmitriev, A., Ed.; Springer: New York, 2012.

(10) Sepúlveda, B.; Angelomé, P. C.; Lechuga, L. M.; Liz-Marzán, L. M. LSPR-Based Nanobiosensors. Nano Today 2009, 4 (3), 244-251.

(11) Ruemmele, J. A.; Hall, W. P.; Ruvuna, L. K.; Van Duyne, R. P. A Localized Surface Plasmon Resonance Imaging Instrument for Multiplexed Biosensing. Anal. Chem. 2013, 85 (9), 4560-4566.

(12) Raphael, M. P.; Christodoulides, J. A.; Delehanty, J. B.; Long, J. P.; Pehrsson, P. E.; Byers, J. M. Quantitative LSPR Imaging for Biosensing with Single Nanostructure Resolution. Biophys. J. 2013, 104 (1), 30-36.

(13) Liu, J.; He, H.; Xiao, D.; Yin, S.; Ji, W.; Jiang, S.; Luo, D.; Wang, B.; Liu, Y. Recent Advances of Plasmonic Nanoparticles and Their Applications. Materials 2018, 11 (10), 1833.

(14) Lopez, G. A.; Estevez, M.-C.; Soler, M.; Lechuga, L. M. Recent Advances in Nanoplasmonic Biosensors: Applications and Lab-on-aChip Integration. Nanophotonics 2017, 6 (1), 123-136.

(15) Jiang, J.; Wang, X.; Li, S.; Ding, F.; Li, N.; Meng, S.; Li, R.; Qi, J.; Liu, Q.; Liu, G. L. Plasmonic Nano-Arrays for Ultrasensitive BioSensing. Nanophotonics 2018, 7 (9), 1517-1531.

(16) Tu, M. H.; Sun, T.; Grattan, K. T. V. LSPR Optical Fibre Sensors Based on Hollow Gold Nanostructures. Sens. Actuators, B 2014, 191, 37-44.

(17) Svedendahl, M.; Chen, S.; Dmitriev, A.; Käll, M. Refractometric Sensing Using Propagating versus Localized Surface Plasmons: A Direct Comparison. Nano Lett. 2009, 9 (12), 4428-4433.

(18) Kabashin, A. V.; Evans, P.; Pastkovsky, S.; Hendren, W.; Wurtz, G. A.; Atkinson, R.; Pollard, R.; Podolskiy, V. A.; Zayats, A. V. Plasmonic Nanorod Metamaterials for Biosensing. Nat. Mater. 2009, 8 (11), 867-871.

(19) Xu, H.; Käll, M. Modeling the Optical Response of Nanoparticle-Based Surface Plasmon Resonance Sensors. Sens. Actuators, B 2002, 87 (2), 244-249.

(20) Chen, H.; Kou, X.; Yang, Z.; Ni, W.; Wang, J. Shape- and SizeDependent Refractive Index Sensitivity of Gold Nanoparticles. Langmuir 2008, 24 (10), 5233-5237.

(21) Saison-Francioso, O.; Lévêque, G.; Boukherroub, R.; Szunerits, S.; Akjouj, A. Dependence between the Refractive-Index Sensitivity of 
Metallic Nanoparticles and the Spectral Position of Their Localized Surface Plasmon Band: A Numerical and Analytical Study. J. Phys. Chem. C 2015, 119 (51), 28551-28559.

(22) Martinsson, E.; Sepulveda, B.; Chen, P.; Elfwing, A.; Liedberg, B.; Aili, D. Optimizing the Refractive Index Sensitivity of Plasmonically Coupled Gold Nanoparticles. Plasmonics 2014, 9 (4), 773-780.

(23) Hooshmand, N.; Bordley, J. A.; El-Sayed, M. A. The Sensitivity of the Distance Dependent Plasmonic Coupling between Two Nanocubes to Their Orientation: Edge-to-Edge versus Face-to-Face. J. Phys. Chem. C 2016, 120 (8), 4564-4570.

(24) Chen, Y. Nanofabrication by Electron Beam Lithography and Its Applications: A Review. Microelectron. Eng. 2015, 135, 57-72.

(25) Zhu, S.; Zhou, W. Plasmonic Properties of Two-Dimensional Metallic Nanoholes Fabricated by Focused Ion Beam Lithography. J. Nanopart. Res. 2012, 14 (3), 652.

(26) Kaye, S.; Zeng, Z.; Sanders, M.; Chittur, K.; Koelle, P. M.; Lindquist, R.; Manne, U.; Lin, Y.; Wei, J. Label-Free Detection of DNA Hybridization with a Compact LSPR-Based Fiber-Optic Sensor. Analyst 2017, 142 (11), 1974-1981.

(27) Yu, C.-C.; Chen, H.-L. Nanoimprint Technology for Patterning Functional Materials and Its Applications. Microelectron. Eng. 2015, 132, 98-119.

(28) Su, H.; Cheng, X. R.; Endo, T.; Kerman, K. Photonic Crystals on Copolymer Film for Label-Free Detection of DNA Hybridization. Biosens. Bioelectron. 2018, 103, 158-162.

(29) Krishnamoorthy, S.; Krishnan, S.; Thoniyot, P.; Low, H. Y. Inherently Reproducible Fabrication of Plasmonic Nanoparticle Arrays for SERS by Combining Nanoimprint and Copolymer Lithography. ACS Appl. Mater. Interfaces 2011, 3 (4), 1033-1040.

(30) Dickreuter, S.; Gleixner, J.; Kolloch, A.; Boneberg, J.; Scheer, E.; Leiderer, P. Mapping of Plasmonic Resonances in Nanotriangles. Beilstein J. Nanotechnol. 2013, 4 (1), 588-602.

(31) Stakenborg, T.; Lagae, L. Gold Nanoring as a Sensitive Plasmonic Biosensor for On-Chip DNA Detection. Appl. Phys. Lett. 2012, 100 (17), 173114.

(32) Qi, X.; Bi, J. Plasmonic Sensors Relying on Nanoparticle Arrays Created by a Template-Directed Dewetting Process. Opt. Commun. 2019, 453, 124328.

(33) Nguyen, D. T.; Kim, D.-J.; Kim, K.-S. Controlled Synthesis and Biomolecular Probe Application of Gold Nanoparticles. Micron 2011, 42 (3), 207-227.

(34) Cant, N. E.; Critchley, K.; Zhang, H.-L.; Evans, S. D. Surface Functionalisation for the Self-Assembly of Nanoparticle/Polymer Multilayer Films. Thin Solid Films 2003, 426 (1-2), 31-39.

(35) Magura, J.; Zeleňáková, A.; Zeleňák, V.; Kaňuchová, M. ThiolModified Gold Nanoparticles Deposited on Silica Support Using Dip Coating. Appl. Surf. Sci. 2014, 315 (1), 392-399.

(36) Schneider, T.; Jahr, N.; Jatschka, J.; Csaki, A.; Stranik, O.; Fritzsche, W. Localized Surface Plasmon Resonance (LSPR) Study of DNA Hybridization at Single Nanoparticle Transducers. J. Nanopart. Res. 2013, 15 (4), 1531.

(37) Thamm, S.; Csàki, A.; Fritzsche, W. LSPR Detection of Nucleic Acids on Nanoparticle Monolayers. Methods Mol. Biol. 2018, 1811, 163-171.

(38) Bonyár, A.; Csarnovics, I.; Veres, M.; Himics, L.; Csik, A.; Kámán, J.; Balázs, L.; Kökényesi, S. Investigation of the Performance of Thermally Generated Gold Nanoislands for LSPR and SERS Applications. Sens. Actuators, B 2018, 255, 433-439.

(39) Roether, J.; Chu, K.-Y.; Willenbacher, N.; Shen, A. Q.; Bhalla, N. Real-Time Monitoring of DNA Immobilization and Detection of DNA Polymerase Activity by a Microfluidic Nanoplasmonic Platform. Biosens. Bioelectron. 2019, 142, 111528.

(40) Bhalla, N.; Sathish, S.; Galvin, C. J.; Campbell, R. A.; Sinha, A.; Shen, A. Q. Plasma-Assisted Large-Scale Nanoassembly of MetalInsulator Bioplasmonic Mushrooms. ACS Appl. Mater. Interfaces 2018, 10 (1), 219-226.

(41) Gartia, M. R.; Hsiao, A.; Pokhriyal, A.; Seo, S.; Kulsharova, G.; Cunningham, B. T.; Bond, T. C.; Liu, G. L. Colorimetric Plasmon
Resonance Imaging Using Nano Lycurgus Cup Arrays. Adv. Opt. Mater. 2013, 1 (1), 68-76.

(42) Zhu, S.; Li, H.; Yang, M.; Pang, S. W. Label-Free Detection of Live Cancer Cells and DNA Hybridization Using 3D Multilayered Plasmonic Biosensor. Nanotechnology 2018, 29 (36), 365503.

(43) Ozaki, Y.; Kneipp, K.; Aroca, R. Frontiers of Surface-Enhanced Raman Scattering; Ozaki, Y., Kneipp, K., Aroca, R., Eds.; John Wiley \& Sons, Ltd.: Chichester, UK, 2014; Vol. 9781118359.

(44) Israelsen, N. D.; Hanson, C.; Vargis, E. Nanoparticle Properties and Synthesis Effects on Surface-Enhanced Raman Scattering Enhancement Factor: An Introduction. Sci. World J. 2015, 2015, 112.

(45) Jin, H. M.; Kim, J. Y.; Heo, M.; Jeong, S.-J.; Kim, B. H.; Cha, S. K.; Han, K. H.; Kim, J. H.; Yang, G. G.; Shin, J.; Kim, S. O. Ultralarge Area Sub-10 Nm Plasmonic Nanogap Array by Block Copolymer SelfAssembly for Reliable High-Sensitivity SERS. ACS Appl. Mater. Interfaces 2018, 10 (51), 44660-44667.

(46) Badilescu, S.; Prakash, J.; Packirisamy, M. Surface Gold and Silver-Polymer Nanocomposite Self-Standing Films. In Handbook of Polymer and Ceramic Nanotechnology; Springer International Publishing: Cham, 2019; pp 1-20.

(47) SadAbadi, H.; Badilescu, S.; Packirisamy, M.; Wüthrich, R. Integration of Gold Nanoparticles in PDMS Microfluidics for Lab-ona-Chip Plasmonic Biosensing of Growth Hormones. Biosens. Bioelectron. 2013, 44 (1), 77-84.

(48) Scarano, S.; Berlangieri, C.; Carretti, E.; Dei, L.; Minunni, M. Tunable Growth of Gold Nanostructures at a PDMS Surface to Obtain Plasmon Rulers with Enhanced Optical Features. Microchim. Acta 2017, 184 (9), 3093-3102.

(49) Spiga, F. M.; Bonyár, A.; Ring, B.; Onofri, M.; Vinelli, A.; Sántha, H.; Guiducci, C.; Zuccheri, G. Hybridization Chain Reaction Performed on a Metal Surface as a Means of Signal Amplification in SPR and Electrochemical Biosensors. Biosens. Bioelectron. 2014, 54 $102-108$.

(50) Guy, R. A.; Xiao, C.; Horgen, P. A. Real-Time PCR Assay for Detection and Genotype Differentiation of Giardia Lamblia in Stool Specimens. J. Clin. Microbiol. 2004, 42 (7), 3317-3320.

(51) Fan, X.; Hao, Q.; Jin, R.; Huang, H.; Luo, Z.; Yang, X.; Chen, Y.; Han, X.; Sun, M.; Jing, Q.; Dong, Z.; Qiu, T. Assembly of Gold Nanoparticles into Aluminum Nanobowl Array. Sci. Rep. 2017, 7 (1), 2322.

(52) Bonyár, A.; Lednický, T.; Hubálek, J. LSPR Nanosensors with Highly Ordered Gold Nanoparticles Fabricated on Nanodimpled Aluminium Templates. Procedia Eng. 2016, 168, 1160-1163.

(53) Ikeda, H.; Iwai, M.; Nakajima, D.; Kikuchi, T.; Natsui, S.; Sakaguchi, N.; Suzuki, R. O. Nanostructural Characterization of Ordered Gold Particle Arrays Fabricated via Aluminum Anodizing, Sputter Coating, and Dewetting. Appl. Surf. Sci. 2019, 465, 747-753.

(54) Lee, W.; Park, S.-J. Porous Anodic Aluminum Oxide: Anodization and Templated Synthesis of Functional Nanostructures. Chem. Rev. 2014, 114 (15), 7487-7556.

(55) Yang, S.; Xu, F.; Ostendorp, S.; Wilde, G.; Zhao, H.; Lei, Y. Template-Confined Dewetting Process to Surface Nanopatterns: Fabrication, Structural Tunability, and Structure-Related Properties. Adv. Funct. Mater. 2011, 21 (13), 2446-2455.

(56) Müller, C. M.; Mornaghini, F. C. F.; Spolenak, R. Ordered Arrays of Faceted Gold Nanoparticles Obtained by Dewetting and Nanosphere Lithography. Nanotechnology 2008, 19 (48), 485306.

(57) Hao, Q.; Huang, H.; Fan, X.; Yin, Y.; Wang, J.; Li, W.; Qiu, T.; Ma, L.; Chu, P. K.; Schmidt, O. G. Controlled Patterning of Plasmonic Dimers by Using an Ultrathin Nanoporous Alumina Membrane as a Shadow Mask. ACS Appl. Mater. Interfaces 2017, 9 (41), 36199-36205.

(58) Kang, M.; Park, S.-G.; Jeong, K.-H. Repeated Solid-State Dewetting of Thin Gold Films for Nanogap-Rich Plasmonic Nanoislands. Sci. Rep. 2015, 5 (1), 14790.

(59) Bae, Y. M.; Jin, S. O.; Kim, I.; Shin, K. Y.; Heo, D.; Kang, D.-G. Detection of Biomarkers Using LSPR Substrate with Gold Nanoparticle Array. J. Nanomater. 2015, 2015, 1-6. 
(60) Kravets, V. G.; Kabashin, A. V.; Barnes, W. L.; Grigorenko, A. N. Plasmonic Surface Lattice Resonances: A Review of Properties and Applications. Chem. Rev. 2018, 118 (12), 5912-5951.

(61) Fischer, L. M.; Tenje, M.; Heiskanen, A. R.; Masuda, N.; Castillo, J.; Bentien, A.; Émneus, J.; Jakobsen, M. H.; Boisen, A. Gold Cleaning Methods for Electrochemical Detection Applications. Microelectron. Eng. 2009, 86 (4-6), 1282-1285.

(62) Hsieh, C. C.; Balducci, A.; Doyle, P. S. Ionic Effects on the Equilibrium Dynamics of DNA Confined in Nanoslits. Nano Lett. 2008, 8 (6), 1683-1688.

(63) Gong, P.; Levicky, R. DNA Surface Hybridization Regimes. Proc. Natl. Acad. Sci. U. S. A. 2008, 105 (14), 5301-5306.

(64) Zhang, X.; Servos, M. R.; Liu, J. Surface Science of DNA Adsorption onto Citrate-Capped Gold Nanoparticles. Langmuir 2012, 28 (8), 3896-3902.

(65) Jia, S.; Bian, C.; Sun, J.; Tong, J.; Xia, S. A WavelengthModulated Localized Surface Plasmon Resonance (LSPR) Optical Fiber Sensor for Sensitive Detection of Mercury(II) Ion by Gold Nanoparticles-DNA Conjugates. Biosens. Bioelectron. 2018, 114, 1521.

(66) Drozd, M.; Pietrzak, M. D.; Malinowska, E. SPRi-Based Biosensing Platforms for Detection of Specific DNA Sequences Using Thiolate and Dithiocarbamate Assemblies. Front. Chem. 2018, 6, 173. 